\title{
Sister Chromatid Cohesion Protein PDS5 Homolog A
}

National Cancer Institute

\section{Source}

National Cancer Institute. Sister Chromatid Cohesion Protein PDS5 Homolog A. NCI

Thesaurus. Code C126610.

Sister chromatid cohesion protein PDS5 homolog A (1337 aa, 151 kDa) is encoded by the human PDS5A gene. This protein plays a role in sister chromatid cohesion in mitosis. 